\title{
Robotic Assisted Ureteric Mitrofanoff Conduit with Malone Antegrade Continence Enema Procedure
}

\author{
Sreeharsha Harinatha*, Mohan Keshavamurthy, Shakir Tabrez, Prem Kumar, Basavaraj Neelagar, Karthik Rao, Santosh Subudhi
}

Fortis hospitals, 154/9, Bannerghatta main road, Bangalore, 560076, India

${ }^{\star}$ Correspondence to: Sreeharsha Harinatha; Fortis hospitals, 154/9, Bannerghatta main road, Bangalore, 560076, India; Tel: +917760200377 ;

E-mail: drsreeharsha@yahoo.com

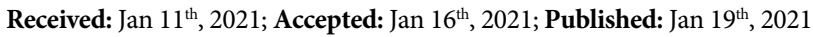

Citation: Harinatha $S^{*}$, Keshavamurthy M, Tabrez S, Kumar P, Neelagar B, Rao K, Subudhi S. Robotic assisted ureteric mitrofanoff conduit with malone antegrade continence enema procedure. Urology Open A Open J. 2021; 2(1): 54. doi: 10.33169/uro.UOAOJ-2-114

\section{INTRODUCTION AND OBJECTIVE}

Neurogenic bladders requiring self catheterizations have primarily been treated using appendix as the preferred mitrofanoff channel. But in some cases appendix may be absent or maybe required for other procedures as in MACE (Malone Antegrade Continence Enema) for chronic constipation. Here we demonstrate the feasibility of Ureter as the Mitrofanoff channel combined with bladder augmentation and MACE procedure done robotically.

\section{MATERIALS AND METHODS}

The patient is a 14 year old male with neurogenic bladder due to spinal dysraphism with inability to do per urethral self intermittent catheterization due to sensitivity and recurrent urinary tract infection. He also had chronic constipation requiring digital evacuation frequently.

Evaluation with urodynamics and cystogram showed poor compliance with small capacity bladder with no reflux. He was planned for Robotic Augmentation Cystoplasty and Ureteric Mitrofanoff conduit with MACE procedure.

The patient was placed in trendelenburg position and standard 4 port docking of Da Vinci XI robot was done with additional assistant port. Ileal segment of $20 \mathrm{~cm}$ was marked with sutures and delivered out of the abdomen through a small suprapubic incision and was partially detubularised and refashioned into an $U$ shaped patch with chimney and was returned to the abdominal cavity. Augmentation of bladder was done with single layer barbed sutures. Right ureter was divided at the lower one third level. Proximal ureter was anastomosed to the ileal chimney and distal ureter was brought out at the right iliac fossa as cutaneous stoma. Appendix was brought out at a separate site for cutaneous stoma for antegrade continence enema.

\section{RESULTS}

Total operative time was approximately 4 hours. Estimated blood loss was about $200 \mathrm{ml}$. Patient was discharged on the 4th postoperative day.
4 weeks after the procedure, DJ stent was removed and patient initiated on self catheterization and antegrade enemas which he was able to do comfortably.

\section{CONCLUSIONS}

Robotic assisted ureteric mitrofanoff procedure with augmentation cystoplasty and MACE procedure is technically feasible with good outcome in selected patients with combined neurogenic bladder and bowel dysfunction.

\section{VIDEO}
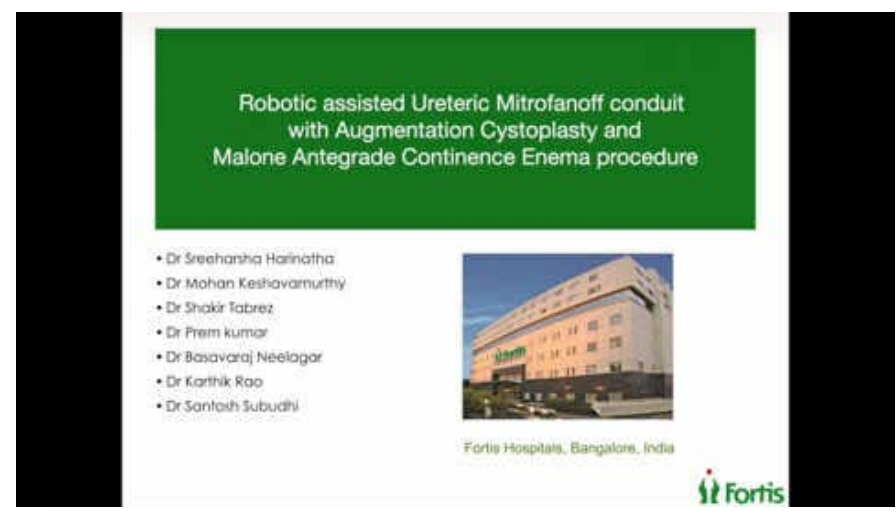

Video link

\section{CONFLICTS OF INTEREST}

None. 